\title{
GASODYNAMIC STUDY OF THE INTAKE ROUTE AT A SPARK-IGNITION ENGINE
}

\author{
Sorin RATIU1, * Vasile ALEXA ${ }^{1}$ \\ ${ }^{1}$ Politehnica University of Timişoara, Faculty of Engineering Hunedoara, Hunedoara, Romania
}

Received (13.05.2016); Revised (14.09.2016); Accepted (19.09.2016)

\begin{abstract}
This study aims at determining, by experiment, the pressure loss occurring on the intake route of a sparkignition engine with carburettor. For this purpose, a pilot plant was designed for measuring the pressure at various points on the route, simulating a stationary air flow regime by means of a vacuum pump. Measurements were made for various lifting heights of the intake valve and various opening positions of the throttle body.
\end{abstract}

Key words: intake valve, pressure loss.

\section{INTRODUCTION}

The components of fresh load entering the engine cylinders during the intake stroke are the fresh air and - in systems with external mixture formation - the fuel (gasoline), in the form of vapours, found in suspension in it. Most of the amount of fresh air enters the cylinders through the channel controlled by the throttle. Additionally, the fresh load can be sucked into the engine through the vapour recirculation system, if it exists. The air mass found in cylinders after closing the intake valve is the decisive factor in relation to the mechanical work produced by cyclically burning of the fresh load, with direct influence on the engine torque. Consequently, the measures to increase the maximum torque and the maximum power almost always involve creating the conditions for obtaining a maximum possible filling ratio [1].

When using carburettors as equipment for achieving the optimal dosage of the fuel mixture, the intake system was characterised by manifolds able to feed one or more cylinders. As a result of its geometry, this system has significant losses of fresh load, leading to lower maximum power and momentum.

On the intake route, two kinds of losses are recorded.

- pressure losses or gasodynamic losses caused by the existence of hydraulic resistances on the suction line, which can be quantified using the well-known relation:

$\Delta p=\xi \cdot \rho \cdot \frac{w^{2}}{2}$

where $\xi$ is the pressure loss coefficient characteristic to each component of the intake system, $w$ is the flow rate of the fresh fluid, and $\rho$ is its density.

- Heat losses caused by fluid heating from the suction line walls, which determine the final temperature to be higher than the engine inlet temperature, the temperature increase resulting in density decrease and, hence, affecting the filling.

To establish a single criterion for quantifying the filling performance, we must compare the amount of load that actually enters the cylinder with the one that might enter if there were no losses.

The filling degree or filling ratio:

$\eta_{v}=\frac{C}{C_{0}}$

is the ratio between the load actually retained in the cylinder (C), after closing the last device for stopping the access of the engine fluid to and from the cylinder, and the amount of load that might be retained in the cylinder $\left(\mathrm{C}_{0}\right)$, in the condition recorded when entering into the engine, per cylinder capacity unit [2].

This study focuses only on the loss of pressure caused by the existence of hydraulic resistances, for finding them by experimental measurements and highlighting their effects on the process of filling the engine cylinders with fresh fluid.

\section{LOSS ON THE ENGINE INTAKE ROUTE}

The fuel mixture is flowing through the intake system under the effect of the depression created by the downward movement of the piston from TDC to BDC, in conjunction with the inertial flow effect and the undulating effect of the pressure waves created by the opening and closing valves. At partial throttle openings, while behind it there is a significant depression, the flow is continuous and not pulsating. At large throttle openings, in which case the flow restrictions are minimal due to the effect of acoustic waves propagation, the movement has a pulsating character.

The size of depression in the sucked engine cylinder depends primarily on the gasodynamic resistances that oppose the fresh load passing through the intake system components: air filter, carburettor diffuser, throttle body, intake manifolds, inlet channel of the cylinder head, intake valve port (seat), and intake valve disk. In general, the depression created by the engine depends on many factors, among which the constructive factors are the most important. In practice, it has been found that the depression increases with increasing rotational speed. 
The gasodynamic losses are caused, on the one hand, by the abrupt section variations when the fresh mixture is passing through the intake manifolds, intake port and valve and, on the other hand, when changing the direction of mixture passing through the bends of the intake system, as well as by the friction with the intake route walls.

The sudden changes of section and direction, along with the mixture friction with the intake route walls, generate vortices whose effect is the pressure drop below the atmospheric pressure, at the end of the filling process. The thermal \& gasodynamic losses during filling with fresh mixture are assessed using the degree of filling as defined above.

The gasodynamic losses are dependent on the flow velocity of the fresh mixture and, implicitly, on the engine rotational speed. Their sizes increase with increasing rotational speed. So, there is a decrease of fresh charge pressure in the cylinder compared to the one had in the environment and, therefore, a reduction in the mass that fills the available volume of the cylinder.

The pressure drops on the system components, such as: air filter, carburettor diffuser, intake manifolds and the intake channel of the cylinder head, have low values. Of particular importance, however, are the pressure drops on the throttle and the one corresponding to the valve port and the intake valve disk, reaching values of $10 \div 20 \%$ of the atmospheric pressure [3].

\section{EXPERIMENTAL RESEARCH. EQUIPMENT AND PROCEDURES}

This study focuses on theoretical analysis, design and practical realisation of a gasodynamic test stand for providing information about how the fresh gases flow through the manifolds, during the intake process. The purpose of using this device is to find the characteristic parameters that emphasize the perfection of filling.

\subsection{How to Choose of the Intake System Model?}

To materialise the gasodynamic studies, we decided to analyse the intake system of a Dacia engine, type 810.99, equipped with CARFIL 32 IRM carburettor, WEBER licence, centrally positioned on the intake manifold. The cylinder head, cast from aluminium alloy, has two valves per cylinder (one inlet and one outlet). The combustion chamber is wedge-type, with the volume of $35.6 \mathrm{~cm}^{3}$. The diameter of the intake valve disk is $33.5 \mathrm{~mm}$ [4]. The reason for choosing this intake system is that it has the highest complexity in terms of the gasodynamic resistances found on the route between the air filter and the interior of cylinder.

\subsection{Research Methodology}

To study the intake process in gasodynamic terms, it is necessary to create the same mechanism governing the gas flow through an internal combustion engine. This mechanism is given by the pressure difference between the interior of cylinder and the outer environment.

In this situation, we considered, as methodology for determining the gas flow parameters, the measurement of the pressure differences created between the outer environment and various points, specially chosen, located on the intake route, including the interior of cylinder, for various lifting heights of the intake valve and various positions of the throttle. With the aid of the measured pressure difference values, we can find the gas flows passing through the intake system and cylinders. With the aid of the measured flows and the theoretically determined flows, on the basis of the geometry of the components crossed by gases, we can find a number of characteristic values of the intake process. Subsequently, we can determine the following parameters: filling degree, flow coefficient of the intake valve, momentary flow coefficient of the hole provided by the intake valve port, resistance coefficient of the intake route, efficiency of flow in the vicinity of the valve, etc.

\subsection{Presentation of the Experimental Stand}

For studying the gas flow, it is necessary to create a depression along the intake route. In accordance with this requirement, the gasodynamic research device must be capable of producing negative pressure.

The stand should be able to measure the pressure difference between the external environment and various points located along the intake route, including the interior of cylinder. Considering these aspects, the embodiment includes the following elements:

- equipment for obtaining the vacuum (vacuum pump);

- device for measuring the pressures and pressure differences;

- carburettor, centrally mounted on the intake manifold;

- cylinder head with holder;

- transparent cylinder;

- device for lifting the intake valve;

- device for measuring the lifting height of the intake valve;

- device used to operate the throttle body and to measure its angular position.

To ensure a good accuracy of the experimental measurements, a depression of $150-600 \mathrm{mmH}_{2} \mathrm{O}$ is required. The depression change should be continuous, for providing constant values for any geometry of the components to be studied. When studying the air flow through the intake valve, depending on its lifting height from the seat, it is required to change the test pressure for reading the small flows circulated by gases. For this reason, the vacuum pump is equipped with devices able to change the circulated flows and the values of the created depressions.
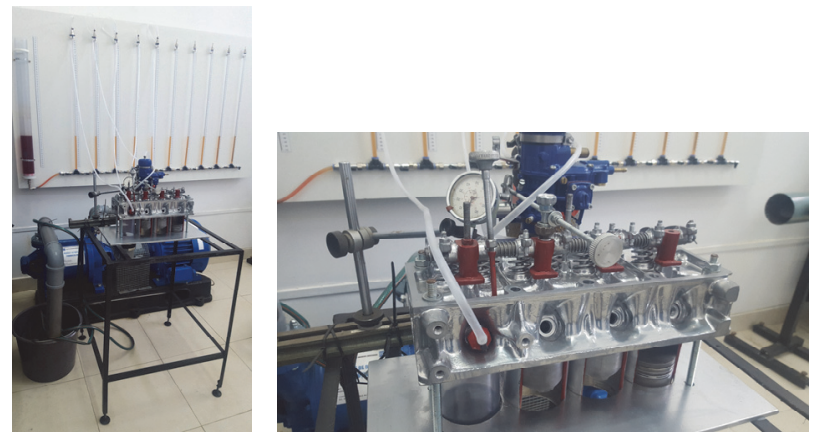

Fig.1. Experimental stand

The measurement of testing pressure values is carried out by using an assembly of manometers with vertical tube filled with liquid. We choose this solution because it 
satisfies the required measurement accuracy and, in addition, it provides a good sensitivity when reading the values representing small pressure changes. The liquid used in the measuring tube is water.

The route of the pressure ports is shown in Fig. 2. They were positioned so as to measure the pressure drop on each representative section of the intake route.

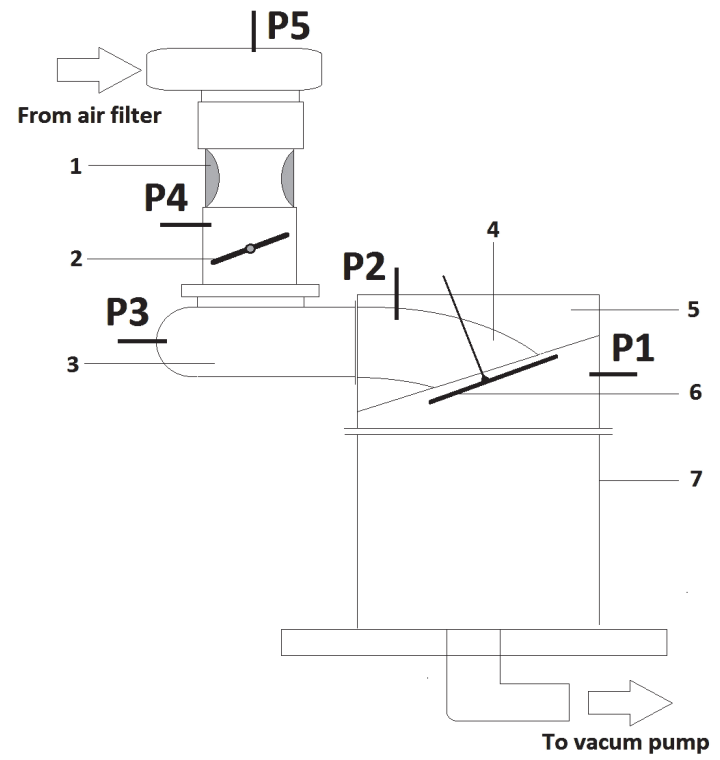

Fig.2. Intake route with the positioning of the pressure ports

The significance of the parts presented in Figure 2 is as follows: 1 - carburettor diffuser, 2 - throttle body, 3 intake manifolds, 4 - intake channel of the cylinder head, 5 - cylinder head, 6 - intake valve, 7 - cylinder, P1...P5 - pressure ports.

The pressure ports are made in the form of holes in the plate-shaped solid wall (Fig. 3) or cylindrical wall (Fig. $4)$, over which the air stream flows.

A pressure port has the diameter $(\phi)$ of $1.5 \mathrm{~mm}$, no burrs, its axis is normal to the cylindrical or plain wall, smooth, placed sideways or sideways-upwards (to avoid possible collection of gaseous inclusions). The flexible pipe is made of transparent plastic material [5].
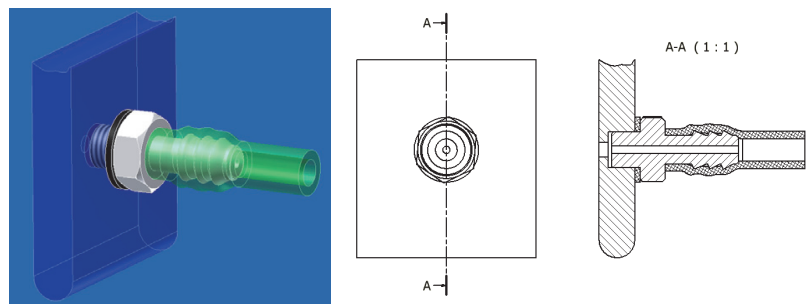

Fig.3. Pressure port in plain wall
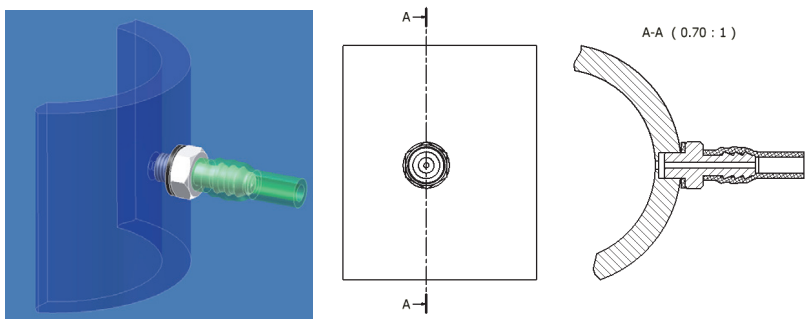

Fig.4. Pressure port in cylindrical wall
We considered 4 positions of the throttle body: $10 \%$ open, $25 \%$ open, $50 \%$ open and $100 \%$ open. For each position of the throttle body, we made measurements for 4 lifting heights of the throttle body, i.e. $0.1 \mathrm{~mm}, 2 \mathrm{~mm}, 4 \mathrm{~mm}, 9$ $\mathrm{mm}$ (maximum lifting height). All this time, the depression produced by the vacuum pump was kept constant. For each flow regime, as defined by all the above combinations, 3 sets of measurement have been made, the final values representing their arithmetic mean.

\section{RESULTS AND CONCLUSIONS}

Hereinafter, we are going to present the results and conclusions of the experimental measurements, specifying that the measured pressure values are relative to the atmospheric pressure.

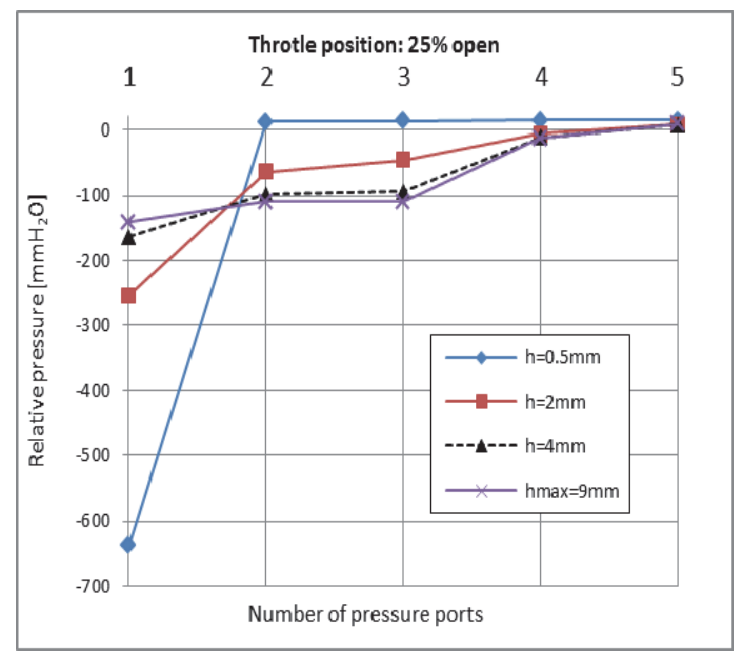

Fig.5. Relative pressure at the 5 ports, for the throttle body position "25\% open"

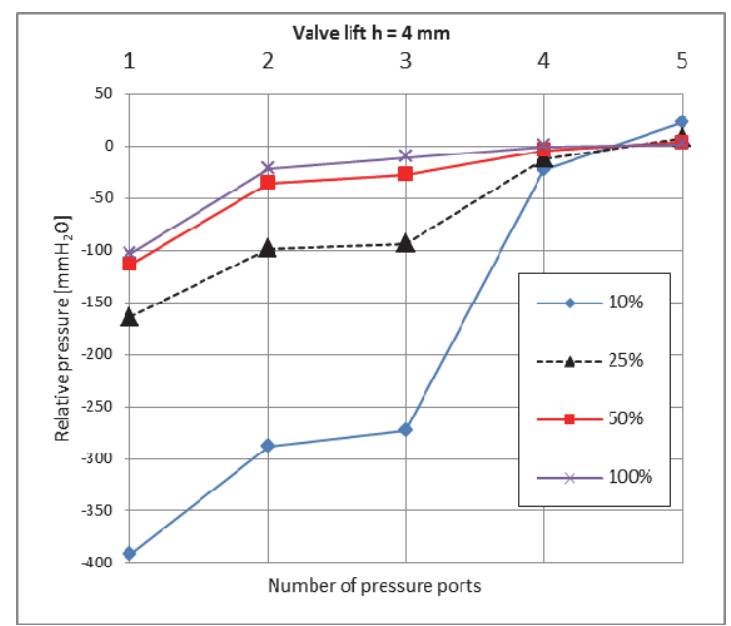

Fig.6. Relative pressure at the 5 ports, for the valve lifting height $h=4 \mathrm{~mm}$

In Figure 5, we can see that the depression values in the measuring points on the intake route, at the same throttle position $(25 \%$ open), increase with increasing lifting height of the valve (h). On the contrary, the pressure differences between two consecutive measuring points (pressure drop or pressure loss) decrease with increasing lifting height of the valve. This is because, with 
increasing lifting height of the valve, the flow area in the vicinity of the valve increases and, consequently, the flow rate of the fluid decreases. A low flow speed means lower pressure losses.

Figure 6 shows that the depression values recorded in the measuring points, when the lifting height of the valve is maintained constant $(\mathrm{h}=4 \mathrm{~mm})$, are decreasing as the throttle opens. We can also see that the loss of pressure when passing in the vicinity of the throttle (pressure difference between the ports no. 3 and 4) is lower the more open the throttle is.

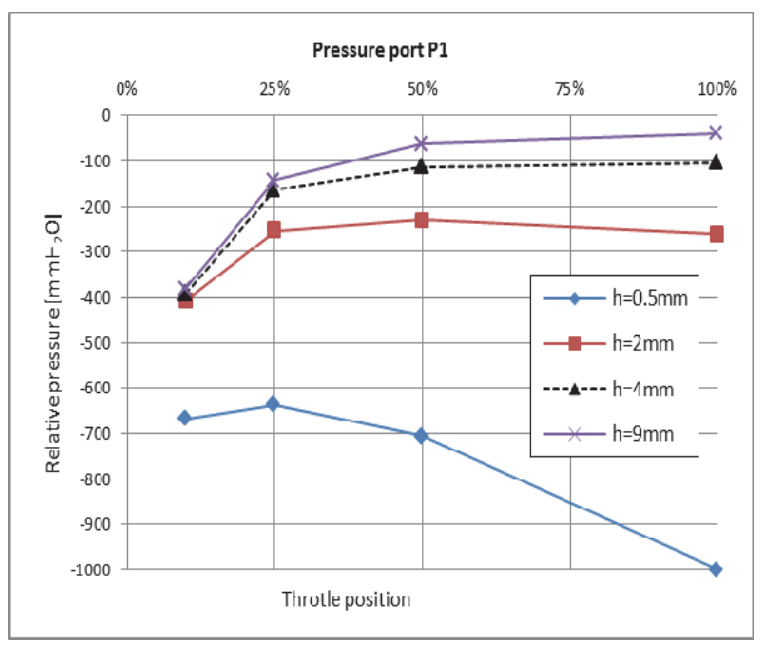

Fig.7. Relative pressure at the port no. 1 versus the valve lifting height and throttle body position

If we focus on the pressure port P1, located in the combustion chamber (Fig. 7), we can say that, at small lifting heights of the intake valve, due to the extremely high pressure losses, at maximum throttle openings, the depression in the combustion chamber is maximal.

\section{REFERENCES}

[1] Automotive Handbook (2007). 7-th Edition, Robert Bosch GmbH.

[2] Raţiu, S., Mihon, L. (2008). Motoare cu ardere internă pentru autovehicule rutiere - Procese şi Caracteristici, Internal combustion engines for road vehicles - Processes and Characteristics, Mirton Publishing House, ISBN 978-973-52-0314-6, Timişoara, Romania.

[3] Leonte, V.L. (2014). Contribuţii privind optimizarea procesului de umplere la motoarele cu ardere internă, Contributions to optimise the filling process at the internal combustion engines, $\mathrm{PhD}$ Thesis, Iaşi, Gheorghe Asachi Technical University, Faculty of Mechanics.

[4] Mondiru, C. (1990). Autoturisme Dacia - Technical book, Technical Publishing House.

[5] Raţiu, S. (2009). Motoare cu ardere internă pentru autovehicule rutiere - Procese şi Caracteristici, Experimente de laborator, Internal combustion engines for road vehicles - Processes and Characteristics. Laboratory experiments, Mirton Publishing House, ISBN 978-973-52-0733-5, Timişoara, Romania.

[6] Abdul, R.I., Rosli, A. B., Semin. (2008). An Investigation of Valve Lift Effect on Air Flow and Coefficient of Discharge of Four Stroke Engines Based on Experiment. American Journal of Applied Sciences 5 (8): 963-971, pp. 963-971, ISSN 15469239.

[7] Ramesh Kumar, C., Nagarajan, G. (2012). Investigation of Flow During Intake Stroke of a Single Cylinder Internal Combustion Engine. ARPN Journal of Engineering and Applied Sciences, Vol.7, Nr.2, (February 2012), pp. 180-186, ISSN 1819-6608.

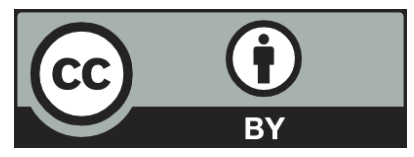

(C) 2017 Authors. Published by the University of Novi Sad, Faculty of Technical Sciences.

This article is an open access article distributed under the terms and conditions of the Creative Commons Attribution license 3.0 Serbia (http://creativecommons.org/licenses/by/3.0/rs/). 